\title{
The progress of catalytic technologies in water purification: A review
}

\author{
LI Dapeng ${ }^{1, *}$, QU Jiuhui ${ }^{2}$ \\ 1. National Natural Science Foundation of China, Beijing 100085, China.E-mail: lidp@mail.nsfc.gov.cn \\ 2. Research Center for Eco-Envrionmental Sciences, Chinese Academy of Sciences, Beijing 100085, China
}

\begin{abstract}
Catalytic technologies have been paid increasing attention in refractory pollutants abatement due to its practical and potential values in water purification. As effective and efficient approaches for water purification, Fenton's reagent, ozonation, electrochemical and photocatalytic methods have been widely studied and applied in different aspects and have been reviewed by several articles. In recent years, some novel catalytic processes based on above processes have been developed for enhancing the efficiency of removing the organics from water. This review emphasized on the recent development of heterogeneous catalytic ozonation, electrocatalysis in respect of novel electrodes and electro-Fenton method, photoelectrocatalysis process and photoelectron-Fenton in water purification. It was also an attempt to propose general ideas about mechanism and principle enhancing the catalytic efficiency for the degradation and the mineralization of organics in water.
\end{abstract}

Key words: catalytic technology; water purification; heterogeneous catalytic ozonation; electrocatalysis; electro-Fenton; photoelectrocatalysis; photoelectro-Fenton

DOI: $10.1016 / \mathrm{S} 1001-0742(08) 62329-3$

\section{Introduction}

The removal of hazardous substances from wastewater and remediation of contaminants in surface water, groundwater is a major problem in the world. Oxidation processes (biological, chemical or physical) are one of major steps during water treatment. Biological oxidation is considered to be economically feasible and widely applicable. Although, the presence of toxic pollutants in treated water might make the usage of this method impossible. Thermal destruction of chemicals at high temperatures, although effective, is not economically feasible. Chemical oxidation with the usage of several oxidants such as ozone, hydrogen peroxide, chlorine or chlorine dioxide generally overcomes these difficulties, although in many cases, it does not result in the total mineralization of water contaminants.

In recent years, catalytic technologies have been described as efficient means for the eliminating of organics pollutants. The technique generally use a combination of oxidation $\left(\mathrm{O}_{3}, \mathrm{H}_{2} \mathrm{O}_{2}\right)$, irradiation, electron and catalyst as a means of generating hydroxyl radicals $(\cdot \mathrm{OH})$, superoxide radicals $\left(\mathrm{O}_{2} \cdot^{-}\right)$and hydroperoxyl $\left(\mathrm{HO}_{2} \cdot\right)$ radicals etc. at ambient temperature and pressure. The synergistic effect from various active species is much more powerful than individuals in enhancing the degradation and mineralization of refractory organic pollutants in water. The oxidative processes can enhance the mineralization efficiency, implying that the final products of degradation reactions are

\footnotetext{
* Corresponding author. E-mail: lidp@mail.nsfc.gov.cn
}

carbon dioxide, short-chain organic acids, and inorganic ions, typically less toxic and amenable to biodegradation. The catalytic technologies predominantly include photocatalysis, electrochemical catalysis photo-electrochemical catalysis, catalytic ozonation, and so on. The application photocatalysis to water purification has been reviewed by several articles (Hoffmann et al., 1995; Mills et al., 1997). From the viewpoint of application to practical water treatment, heterogeneous catalytic ozonation, electrocatatalysis, electron-Fenton, photoelectrocatalysis process, and photoelectron-Fenton will be presented in the following sections, concerning the synergistic effects of photo- and electro-catalysis, the catalytic materials and catalytic degradation process of contaminants.

\section{Heterogeneous catalytic ozonation}

Heterogeneous catalytic ozonation has received increasing attention in recent years due to its potentially higher effectiveness in the degradation and the mineralization of refractory organic pollutants and a lower negative effect on water quality. The major advantage of a heterogeneous over a homogeneous catalytic system is the ease of catalytic retrieval from the reaction media. It has been developed to overcome the limitations of ozonation processes, such as the formation of byproducts and the selective reactions of ozone, which are designed to enhance the production of -OH. Co-based catalysts, such as $\mathrm{Co} / \mathrm{SiO}_{2}$ (Rakitskaya et al., 1999), $\mathrm{CoO} x / \mathrm{Al}_{2} \mathrm{O}_{3}$ (Konova et al., 2006), have 
been used in ozone decomposition studies. In the case of $\mathrm{CoO} x / \mathrm{Al}_{2} \mathrm{O}_{3}$ catalyst, the high oxidation activity in the presence of ozone has been ascribed to the high content of active and mobile oxygen which strongly depends on the preparation method. Gruttadauria et al. (2007) and Liotta et al. (2006) synthesized four series of cobalt-based catalysts, bare oxides $\mathrm{CO}_{3} \mathrm{O}_{4}$ and $\mathrm{CoO}, \mathrm{CoO} x-\mathrm{CeO}_{2}$ mixed oxides, $\mathrm{CoO} x$ supported over alumina, and alumina-baria, and $\mathrm{CoMgAl}$ and $\mathrm{CoNiAl}$ hydrotalcites for the oxidative degradation of phenol in the presence of ozone. The CoNiAl material showed the highest activity, after $4 \mathrm{~h}$ of reaction the TOC removal was of $90 \%$, however, a high amount of $\mathrm{Ni}^{2+}$ were also detected in solution $(17 \mathrm{mg} / \mathrm{L})$. Therefore, the attainment of active and stable catalysts for catalytic ozonation of organic pollutants in water is still a challenge.

Among recent research works on catalytic ozonation, some promising results obtained ( $\mathrm{Hu}$ et al., 2008; Xing et al., 2008). Two series of catalysts, $\mathrm{MnO} x$ and $\mathrm{CoO} x$ supported over ordered mesoporous $\mathrm{ZrO}_{2}(\mathrm{MZ})$ have been synthesized by wet impregnation, drying, water washing and calcinations with manganese acetate tetrahydrate as the metal precursor. XPS and ICP results showed that $\mathrm{Mn}$ and Co were highly dispersed into the pore channels and the surface of $\mathrm{MZ}$. As reference, commercial $\mathrm{ZrO}_{2}$ (CZ), which has nonporosity, smaller surface area and insufficient surface hydroxyls, was used as support. By the same method, little $\mathrm{Mn}$ and Co were loaded on the surface of $\mathrm{CZ}$, and the dosages of $\mathrm{Mn}$, Co were almost completely washed out with water in the step of water washing. These results suggested that the rich surface hydroxyl groups of $\mathrm{MZ}$ played an important role in the loading of $\mathrm{MnO} x$, $\mathrm{CoO} x$. These phenomena indicated that $\mathrm{MnO} x$ or $\mathrm{CoO} x$ was anchored on the surface of $\mathrm{MZ}$ by the interaction of $\left(\mathrm{Mn}\left(\mathrm{H}_{2} \mathrm{O}\right)_{6}\right)^{2+}$ or $\left(\mathrm{Co}\left(\mathrm{H}_{2} \mathrm{O}\right)_{6}\right)^{2+}$ with the surface hydroxyls of the support. In preparation, during impregnation and subsequent drying in air, the complex reacted with both the acidic and basic hydroxyls of $\mathrm{MZ}$ to form the linking $\left(\mathrm{H}_{2} \mathrm{O}\right) x \mathrm{Mn}^{2+/ 3+}-\mathrm{O}-\mathrm{Zr}$ or $\left(\mathrm{H}_{2} \mathrm{O}\right) x \mathrm{Co}^{2+/ 3+}-\mathrm{O}-\mathrm{Zr}$. Then, the excess $\mathrm{Mn}$ or $\mathrm{Co}$, which was not connected directly to the surface of MZ, was almost completely washed out with water in the washing step. Thus, monolayer-dispersed $\mathrm{MnO} x$ or $\mathrm{CoO} x$ was formed by calcination. Therefore, the higher dispersions of $\mathrm{MnO} x$ and $\mathrm{CoO} x$ on $\mathrm{MZ}$ were attributed to the fixing role of surface hydroxyls and the diffusing role of water.

The catalytic activity of $\mathrm{MnO} x / \mathrm{MZ}$ and $\mathrm{CoO} x / \mathrm{MZ}$ was evaluated by the degradation of 2,4-D (2,4dichlorophenoxyacetic acid) with ozone at pH 7 (Fig. 1). Obviously, more than $90 \%$ of total organic carbon (TOC) of 2,4-D were removed within $30 \mathrm{~min}$ in $\mathrm{MnO} x / \mathrm{MZIW}$ and $\mathrm{CoO} x / \mathrm{MZIW}$ suspensions with ozone, While $50 \%$ of TOC of 2,4-D were removed in $\mathrm{MnO} x / \mathrm{CZI}$ suspensions with ozone. In contrast, only $28 \%$ of TOC for $2,4-\mathrm{D}$ were removed at the same reaction time in the presence of ozone alone. The results verified that the multivalence oxidation states and the high dispersion of $\mathrm{MnO} x$ and $\mathrm{CoO} x$ enhanced the electron transfer, causing a higher catalytic reactivity. Also, more than $90 \%$ of TOC of

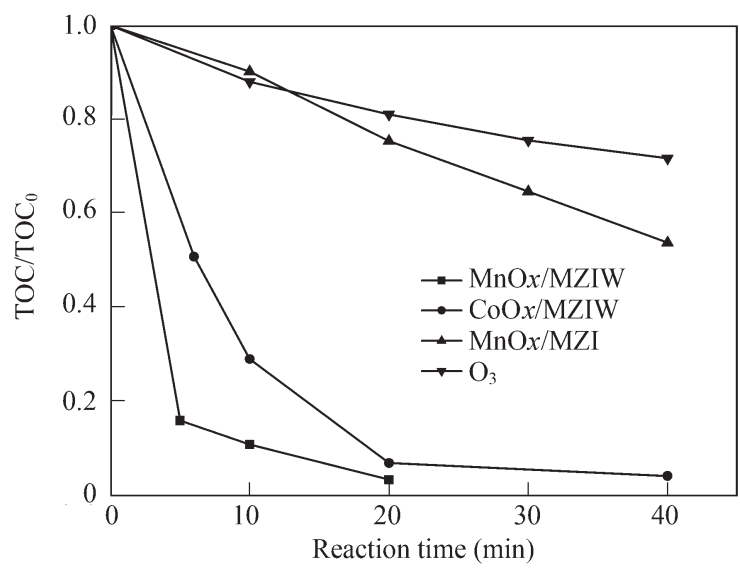

Fig. 1 The removal of TOC during the degradation of 2,4-D $(10 \mathrm{mg} / \mathrm{L})$ in aqueous dispersions of various catalysts with ozone. Conditions: $\mathrm{pH} 7$; catalyst $1.5 \mathrm{~g} / \mathrm{L}$; gaseous ozone concentration $30 \mathrm{mg} / \mathrm{L}$.

Ibuprofen was removed by the catalytic ozonation of MnOx/MZIW and CoOx/MZIW. By GC-MS analysis, the residue intermediates mainly were acetic acid, formic acid etc. aliphatic acid. The catalytic ozonation efficiency of these catalysts did not change greatly in the $\mathrm{pH}$ range $3.5-$ 10.

Similarly, $\mathrm{CuO} x$ was highly dispersed on mesoporous $\gamma-\mathrm{Al}_{2} \mathrm{O}_{3}$ by an impregnation method with an aqueous solution of copper nitrate (Qu et al., 2004). The catalyst exhibited high efficiency for the mineralization of alachlor. The removal rate of alachlor in TOC was more than $60 \%$ in $\mathrm{CuOx} / \mathrm{Al}_{2} \mathrm{O}_{3}$ suspension with ozone while it was only $20 \%$ with ozone alone. Moreover, the studies of electron spin resonance and the effect of radical scavengers indicated that the more $\cdot \mathrm{OH}$ radicals were resulted from the catalytic decomposition of ozone, inducing a higher effectiveness for the removal of refractory pollutants in water. The durable experiments of $\mathrm{MnO} x / \mathrm{MZ}, \mathrm{CoO} x / \mathrm{MZ}$ and $\mathrm{CuO} x / \mathrm{Al}_{2} \mathrm{O}_{3}$ revealed that these catalysts were stable and the concentration of the released metal ions from the catalyst was lower than $0.2 \mathrm{mg} / \mathrm{L}$. These results suggest that catalytic ozonation with $\mathrm{MnO} x / \mathrm{MZ}, \mathrm{CoO} x / \mathrm{MZ}$ and $\mathrm{CuO} x / \mathrm{Al}_{2} \mathrm{O}_{3}$ is a promising technique for the mineralization of refractory organic compounds in water.

\section{Electrocatalysis process}

The electrochemical technology and its application in water purification have received world wide attention in the past decades, due to its advantages such as small reactor size, low land area demand, and easy to handle (Simonsson, 1997). The introduction of catalytic reaction into electrochemical technology, which is called as electrocatalytic technology, would not only notably increase the efficiency and decrease the cost, but also broaden its availability for the degradation of the recalcitrant pollutants (Rajeshwar et al., 1994; Rodger and Bunce, 2001). In this article, we will focus on the review of the electrocatalytic oxidation in respect of high efficient electrodes and electroFenton method. 


\subsection{Electrocatalytic oxidation}

The electrooxidation reactions mainly occur in the anodic compartment, which contributes to the conversion and/or the combustion of organic pollutants. Generally, the pollutants are degraded through the following two pathways: (1) the interactions between pollutants and anode, which is called direct oxidation; (2) the interactions between pollutants and oxidants (e.g., hydroxyl radicals, ozone, hydrogen peroxide, and hypochlorite) formed by the electrode reaction, which is called mediate oxidation. The catalysis during electrooxidation may be promoted through the modification and the adulteration of certain metal oxides (e.g., $\mathrm{PbO}_{2}, \mathrm{MnO}_{2}$ ) on the surfaces of electrode. Additionally, the introduction of homogeneous and heterogeneous catalyzer into the reactor may also be valuable.

The improvement of the efficiency of electrochemical technique is of crucial importance for its application in practice. For example, various electrodes including $\mathrm{Ti}$ and Pt mesh (Boscoletto et al., 1994), Pt/Ti (Tanaka et al., 1999), $\mathrm{SnO}_{2} / \mathrm{Ti}$ (Tanaka et al., 2002), and carbon fiber (Kuramitz et al., 2004) electrodes, have been evaluated for the electrochemical removal of Bisphenol A (BPA). However, $\mathrm{Ti}, \mathrm{Pt}$ and $\mathrm{Pt} / \mathrm{Ti}$ electrodes were not effective to achieve total mineralization of BPA due to electrode deactivation and poor generation of more hydroxyl radicals.

In the past several years, much effort has been devoted to the development of the electrodes with higher catalytic activity. Electrochemical properties of Polyoxometalates (POMs) have been intensively studied in recent years (Sadakane and Steckhan, 1998). An important reason is the ability of POMs anions to accept various numbers of electrons giving rise to mixed-valency species, which has made these compounds very attractive in electrode modification and electrocatalytic research (Sadakane and Steckhan, 1998). It is reported that POMs can been immobilized on ordered mesoporous carbon (OMC) to improve the catalytic activity (Lapkin et al., 2003). It has already been established that POMs molecules can be firmly physically adsorbed to graphite materials (Schwegler et al., 1992). This physical adsorption was an electrostatic attraction caused by proton transfer from POMs to graphite for modifying graphite materials with POMs (Schwegler et al., 1992).

Additionally, the boron-doped diamond (Si/BDD) electrode also received great attention, and has been proved as successful anode material to destruct a variety of organic pollutants. It has many unique advantages and is largely generating the adsorbed hydroxyl radicals from water decomposition as shown in Eq. (1) (Murugananthan et al., 2008).

$\mathrm{BDD}+\mathrm{H}_{2} \mathrm{O} \longrightarrow \mathrm{BDD}(\cdot \mathrm{OH})_{\mathrm{ads}}+\mathrm{H}^{+}+\mathrm{e}^{-}$

$\mathrm{PbO}_{2}$ calls the attention as an electrode material due to its easy and rapid preparation, besides being of low cost and quite stable in high-applied potentials in media of different pHs (Andrade et al., 2008). Its electrocatalytical activity as well as its stability can be significantly improved by the incorporation of doping ions, such as $\mathrm{Fe}^{3+}, \mathrm{Bi}^{3+}$, $\mathrm{Co}^{2+}$, and $\mathrm{F}^{-}$, into its crystalline matrix, acting as good dopants towards the oxygen transfer reaction, as well as ozone production.

In recent year, there were some progresses on the electrocatalytic oxidation. Wang et al. (2006a) investigated the electrochemical degradation of Acid Red B (ARB), with $\mathrm{ACF}$ as an anode or a cathode, respectively. The complete decoloration and the satisfactory mineralization of ARB was achieved under both conditions. Comparatively, the mineralization rate of ACF cathode system (70\% TOC removal) was much higher than that of ACF anode system (30\% TOC removal), owing to the much higher hydroxyl radical concentration in ACF cathode system.

Wang et al. (2006b) investigated the combined effects of electrooxidation and coagulation on the removal of pollutants (i.e., ARB) from solution. The pellets of manganese mineral in a fixed bed mode were arranged to two electrochemical compartments. In anode compartment, manganese mineral may catalyze the electrooxidation of organics, while in cathode compartment, the metal ions dissolved from minerals might form coagulate. The coagulant could flocculate and adsorb the organic pollutants. It was observed that the elimination rate of ARB remarkably increased when the electrolysis process was catalyzed by manganese mineral. After $480 \mathrm{~min}$ of treatment, the TOC removal percentage was $43.6 \%$, while the removal percentages of the process using the manganese mineral alone and using the electrolysis alone were $9.3 \%$ and $20.8 \%$, respectively, suggesting the catalytic effects of manganese minerals on the electro degradation of ARB.

\subsection{Electro-Fenton process}

The study of more efficient electrochemical methods for water purification based on the indirect electro-oxidation of contaminants involving electrogeneration of strong oxidants is also in progress. An increasing number of publications deal with the destruction of toxic and refractory organic pollutants in acid waters by electro-Fenton method (Brillas et al., 1998, 2000; Panizza and Gerisola, 2001; Flox et al., 2006; Irmark et al., 2006; Xie and Li, 2006). The process based on the simultaneous electrogeneration of hydrogen peroxide from the two-electron reduction of $\mathrm{O}_{2}$ on the cathode and the reduction of ferric ion to ferrous ion. The EF process consists of the following steps (Reactions (2)-(5)) (Oturan, 2000).

$$
\begin{aligned}
& \mathrm{O}_{2}+2 \mathrm{H}^{+}+2 \mathrm{e}^{-} \longrightarrow \mathrm{H}_{2} \mathrm{O}_{2} \\
& \mathrm{Fe}^{2+}+\mathrm{H}_{2} \mathrm{O}_{2}+\mathrm{H}^{+} \longrightarrow \mathrm{Fe}^{3+}+\mathrm{H}_{2} \mathrm{O}+\cdot \mathrm{OH} \\
& \mathrm{Fe}^{3+}+\mathrm{e}^{-} \longleftrightarrow \mathrm{Fe}^{2+} \\
& \mathrm{H}_{2} \mathrm{O} \longleftrightarrow 1 / 2 \mathrm{O}_{2}+2 \mathrm{H}^{+}+2 \mathrm{e}^{-}
\end{aligned}
$$

Carbon is widely used as a cathode material for $\mathrm{H}_{2} \mathrm{O}_{2}$ generation because it exhibits a wide range of electrochemical activity for $\mathrm{H}_{2} \mathrm{O}_{2}$ decomposition (Panizza and Gerisola, 2001). Activated carbon fiber (ACF) is a potential carbon material with characteristics of adsorption, conductivity and catalysis (Jia et al., 1999). Because of its large surface area, ACF possesses high adsorption capacity. 
Another benefit of ACF is that ACF felt promoted the electrogeneration of hydrogen peroxide from the two-electron reduction of $\mathrm{O}_{2}$ on its surface, which favors the occurrence of electro-Fenton reactions if $\mathrm{Fe}^{2+}$ is additionally added (Drogui et al., 2001).

Wang et al. (2005a) found that the $\mathrm{H}_{2} \mathrm{O}_{2}$ electrogeneration with ACF felt cathode $(600 \mathrm{mmol} / \mathrm{L})$ was much higher than that with graphite cathode $(52 \mathrm{mmol} / \mathrm{L})$ after $180 \mathrm{~min}$ of electrolysis, which contributed to the more significant TOC removal. The adsorption of AR14 onto ACF felt may be neglected, which led to a limit removal of about $6 \%$ after $360 \mathrm{~min}$. The anodic oxidation, which employed $\mathrm{RuO}_{2} / \mathrm{Ti}$ as anode, only contributed $19 \%$ to TOC removal. The employment of ACF felt as a cathode notably improved the degradation of AR14, which was further enhanced through the addition of $1 \mathrm{mmol} / \mathrm{L} \mathrm{Fe}^{2+}$ and the occurrence of electro-Fenton reactions. The significant acceleration in the presence of $\mathrm{Fe}^{2+}$ could be ascribed to the existence of fast homogeneous reaction of organics with the great amounts of $\cdot \mathrm{OH}$ generated, which nonselectively oxidize most organics remained in the system. Additionally, it was observed that the production of $\mathrm{H}_{2} \mathrm{O}_{2}$ may be promoted through the increase of current densities, therefore enhancing the degradation of organics. The $\mathrm{Fe}^{2+}$ dosage also significantly affected the degradation of AR14. An obvious increase of the rate of TOC decay was observed by adding $\mathrm{Fe}^{2+}$. Raising initial $\mathrm{Fe}^{2+}$ concentrations from 0 to $1 \mathrm{mmol} / \mathrm{L}$ might result in an augmentation of TOC removal. However, the $\mathrm{Fe}^{2+}$ at higher concentrations exhibited adverse effects on TOC removal, due to the scavenging of $\cdot \mathrm{OH}$ by $\mathrm{Fe}^{2+}$.

The electro-Fenton reaction with an ACF felt cathode also promisingly contributed to the degradation of algae microcystins (MC-RR, MR-LR) (Wang et al., 2005b). Quantitatively, $75 \%$ of MC-RR and 94\% MC-LR were eliminated after $60 \mathrm{~min}$ electrolysis under the operation conditions of $6.6 \mathrm{~mA} / \mathrm{cm}^{2}$ current density, $1.0 \mathrm{mmol} / \mathrm{L}$ $\mathrm{Fe}^{2+}$ at $\mathrm{pH}$ 3. ACF not only increased the efficiency of $\mathrm{O}_{2}$ utilization and the formation of $\mathrm{H}_{2} \mathrm{O}_{2}$ due to its high BET surface area, but also contributed to the adsorption and accumulation of microcystins, which was beneficial to microcystins degradation.

\section{Photoelectrocatalysis process}

Heterogeneous photocatalysis using semiconductor oxides, such as $\mathrm{TiO}_{2}$ and $\mathrm{WO}_{3}$, has demonstrated to be very effective to treat pollutants in water (Ioannis and Triantafyllos, 2004, Balasubramanian et al., 2004). Nevertheless, it encountered difficulties of separation and recovery when powder catalysts were used. However, for the fixation of $\mathrm{TiO}_{2}$, the most drawback is that the catalytic efficiency is too low to be used for the removal of pollutants. Furthermore, the high degree of recombination between photogenerated electrons and holes is sometimes a major limiting factor controlling photocatalytic efficiency (Vinodgopal et al., 1993; Li et al., 2000). Recently, the separation of photogenerated electrons and holes was proved to be accelerated by the application of an anodic bias to
$\mathrm{TiO}_{2}$ film; and the lifetime of active holes and electrons was largely extended. As a result, the efficiency of photocatalysis was greatly enhanced (Ward and Bard, 1982). The rate of photocatalytic degradation of 4-chlorophenol increased greatly when the $\mathrm{TiO}_{2}$ particulate film electrode was maintained at an external anodic bias $(0.6 \mathrm{~V}$ versus SCE) (Vinodgopal et al., 1993). Zlamal and his co-workers investigated the influence of an externally applied bias on the photocatalytic performance of self-organized $\mathrm{TiO}_{2}$ nanotube layers. The nanotube layers were grown directly on $\mathrm{Ti}$ substrate by anodization of titanium in fluoride containing electrolytes and have different geometric dimensions. The photocatalytic activity of self-organized $\mathrm{TiO}_{2}$ nanotube layers can significantly be increased by electrochemical bias (Zlamal et al., 2007).

The main advantage of photoelectrocatalysis is its great versatility joined to the simplicity of the reactor in terms of construction and management. However, for the application at large scale, the main limitation is to find electrode materials with specific characteristics to make the process competitive. $\mathrm{Ti} / \mathrm{PbO}_{2}, \mathrm{Ti} / \mathrm{SnO}_{2}, \mathrm{Ti} / \mathrm{IrO}{ }_{2}$, glassy carbon are generally used (Augugliaro et al., 2006). A series of $\mathrm{TiO}_{2}$-modified $\beta-\mathrm{PbO}_{2}$ electrodes were prepared using co-deposition method and characterized by SEM and XRD (Li et al., 2005, 2006a, 2006b). The results indicated that the modified $\beta-\mathrm{PbO}_{2}$ electrodes were different from the unmodified ones. Compared with the unmodified one, the modified $\beta-\mathrm{PbO}_{2}$ electrodes crystals became finer and the electrode became more compact and more uniform. The modified electrodes were used in electrochemically assisted photocatalytic degradation of dyes. In this process, a significant synergetic effect was observed between photocatalytic process and an externally applied electric field on the anode. Table 1 shows the kinetics parameters for different degradation methods (Li et al., 2006a). The results showed that the degradation efficiencies were greatly enhanced when a potential across the electrodes (1.5 $\mathrm{V})$ is applied. $\mathrm{TiO}_{2}$ is scattered between $\mathrm{PbO}_{2}$ crystals, and $\mathrm{PbO}_{2}$ shows similar electrical conductivity to that of the metals, which is favorable in terms of electrocatalysis. Anodic bias potential provides a potential gradient within the photocatalyst layer to drive the electrons to the counter electrode along conductive $\mathrm{PbO}_{2}$ crystals. This contributes to the inhibition of electron-hole recombination processes.

With an increase of $\mathrm{TiO}_{2}$ amount used in codeposition solution, degradation efficiencies were improved to some extent for the modified $\beta-\mathrm{PbO}_{2}$ electrodes. Photocatalytic efficiency was greatly enhanced by the application of

Table 1 Kinetics parameters for different degradation methods*

\begin{tabular}{lll}
\hline Degradation method & $K_{\text {app }}\left(\times 10^{-3} \mathrm{~min}^{-1}\right)$ & $R$ \\
\hline UV irradiation & 1.31 & 0.99 \\
Electrolysis & 0.65 & 0.94 \\
UV with disconnected electrodes & 1.77 & 0.99 \\
EAPD 1st time & 3.84 & 0.93 \\
EAPD 7th time & 2.83 & 0.99 \\
EAPD 1st time, $\mathrm{Ru}_{0.3} \mathrm{Ti}_{0.7} \mathrm{O}_{2}$ & 1.06 & 0.95 \\
\hline * 1.5 V potential was applied across the electrodes when needed, at \\
neutral pH (Li et al., 2006a).
\end{tabular}


an external anodic bias when using Acid Orange 7 as model pollutant. The combination of photocatalysis and externally applied electric field was an effective way to improve the efficiency of photocatalytic process, which demonstrated its potential applicability in the process of photoelectrochemical decontamination for organic pollutants.

Anodic oxidation with boron-doped diamond (BDD) anodes is a new advanced oxidation process with many advantages as compared to other known electrode materials due to its low and stable background current, wide working potential window, and stable surface microstructure over a wide potential range (Wang and Farrell, 2004). The outstanding electrochemical properties of BDD recommend this material as an excellent substrate for electrocatalytic oxide layer in anode oxidation of organic contaminants (Chen et al., 2003). The oxidation process at BDD anodes involves the production of $\cdot \mathrm{OH}$ radicals scarcely adsorbed at the BDD surface: they consequently desorb and can attack the organic pollutant (Augugliaro et al., 2006). Moreover, the BDD electrode exhibit ptype semiconductor properties. A novel configuration of hybrid electrode has been designated as photoelectrocatalytic diodes (PECD) by $\mathrm{Qu}$ and Zhao (2008). These contain nanoislands of n-type $\mathrm{TiO}_{2}$ interfaced over a highly crystalline layered BDD electrode, yielding nanodimensional p-n junctions. This hybrid electrode exhibit high photoelectrocatalytic activities toward the degradation of Acid Orange II (AOII) and 2,4-dichloropheonl (2,4-DCP) due to the p-n effect and high electrocatalytic and photocatalytic activities of BDD electrode and $\mathrm{TiO}_{2}$ particles. Atom force microscopy (Fig. 2) and scanning electron microscopy showed that the $\mathrm{TiO}_{2}$ deposits consist of adherent nanomicro-sized particles, scattered on the BDD substrate. AOII and 2,4-DCP in a solution can be efficiently degraded at the hybrid electrode in the photoelectrocatalysis process. Some intermediates formed in electro-oxidation process such as phenols could not be detected in the photoelectrocatalysis process.

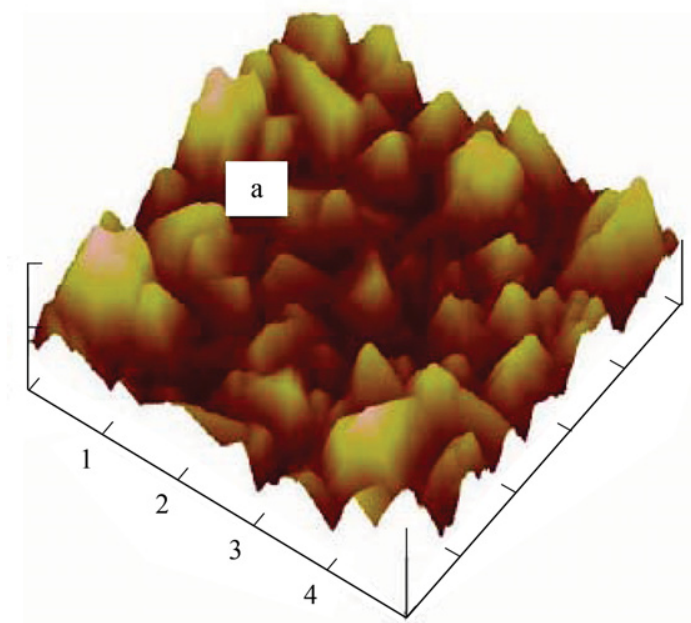

\section{Photoelectro-Fenton process}

Recently, there is increasing interest in the use of photoelectron-Fenton method for pollutant abatement (Boye 2003; Sirés, 2007; Skoumal et al., 2008). The mineralization process can be accelerated by introduced UV light into electro-Fenton process. UV light can accelerate the mineralization process by: (1) the photodecomposition of complexes of $\mathrm{Fe}^{3+}$ with generated carboxylic acids, e.g., oxalic acid. That is, at acidic $\mathrm{pH}$, oxalic acids behave as photo-active complexes in the presence of ferric ions which undergoes photo-decarboxylation reaction (Irmak et al., 2006):

$\mathrm{Fe}(\mathrm{III})\left(\mathrm{RCO}_{2}\right)^{2+}+h v \longrightarrow \mathrm{Fe}^{2+}+\mathrm{CO}_{2}+\mathrm{R} \cdot$

and (2) the regeneration of more $\mathrm{Fe}^{2+}$ from the additional photoreduction of $\mathrm{Fe}(\mathrm{OH})^{2+}$, which is the predominant $\mathrm{Fe}^{3+}$ species in acid medium (Sires et al., 2006):

$\mathrm{Fe}(\mathrm{OH})^{2+}+h v \longrightarrow \mathrm{Fe}^{2+}+\cdot \mathrm{OH}$

The recent study of the herbicide 2,4,5trichlorophenoxyacetic acid (2,4,5-T), performed in an undivided cell with a $\mathrm{Pt}$ anode and an $\mathrm{O}_{2}$-diffusion cathode, showed that the photoelectrochemical process was more powerful than electro-Fenton process, which can yield only about $60 \%-65 \%$ of decontamination. The electro-Fenton method provides complete destruction of all reaction intermediates, except oxalic acid, which in the presence of $\mathrm{Fe}^{3+}$ forms stable complexes that remain in the solution. The fast photodecarboxylation of such Fe(III)-oxalate complexes by UV light explains the highest oxidative ability of the photoelectro-Fenton treatment, which allows the highest mineralization of highly concentrated acidic aqueous solutions of 2,4,5-T at low current and temperature (Brillas et al., 2003).

The mineralization of an azo dye Acid Red 14 (AR14) by the photoelectro-Fenton process was studied recently by Wang et al. (2008). The process was studied in an undivided electrochemical reactor with $\mathrm{RuO}_{2} / \mathrm{Ti}$ anode and an

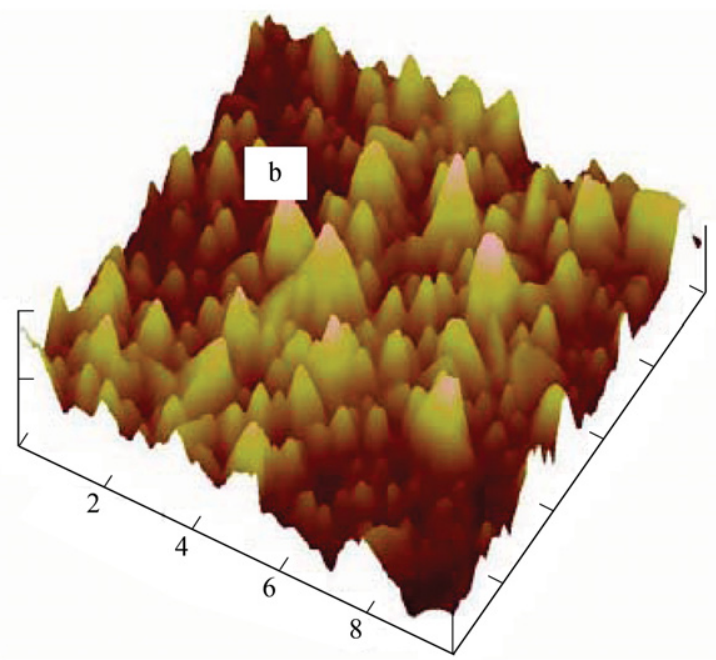

Fig. 2 Atom force microscopy images of $\mathrm{BDD}$ electrode (a) and $\mathrm{BDD}^{-\mathrm{TiO}_{2}}$ hybrid electrode (b). Scale size $10.0 \mu \mathrm{m}$; data scale $350 \mathrm{~nm}$. 
ACF cathode able to electrochemically generate $\mathrm{H}_{2} \mathrm{O}_{2}$. Results indicate that the electro-Fenton process yielded about $60 \%-70 \%$ mineralization of AR14, while the photoelectroFenton could mineralize AR14 more effectively (more than 94\% TOC removal) even at low current densities assisted with UV irradiation after $6 \mathrm{~h}$ electrolysis. The initial solution $\mathrm{pH}$ range 1.49-6.72 has little influence on the TOC removal because of the $\mathrm{pH}$ change during AR14 degradation in the photoelectro-Fenton process, which may be due to the formation of organic carboxylic acids such as oxalic acid. The ACF cathode showed a long-term stability during multiple experimental runs for the degradation of AR14, indicating its good potential for practical application in treating refractory organic pollutants in aqueous solutions.

\section{Conclusions}

The catalytic technologies have the great potential for water purification as demonstrated in the all above studies. At present, its application is mainly limited to laboratory or small scale use. However, due to these successful results, further investigation is to be carried out to handle some key problems, such as the development of novel catalytic materials, the visual light and the combination of different processes and so on. Especially, for the engineering application, more efforts are required to use available information on these tested catalytic process systems, which is mostly on a laboratory scale for the design of pilot-scale reactors applicable for the efficient treatment of industrial wastewater and drinking water.

\section{Acknowledgments}

The authors are grateful to Dr. Liu Huijuan, Dr. Hu Chun, and Dr. Liu Ruiping for their valuable contribution for this article.

\section{References}

Andrade L S, Rocha-Filho R C, Bocchi N, Biaggio S R, Iniesta J, Garcła-Garcia V, Montiel V, 2008. Degradation of phenol using Co- and $\mathrm{Co}$, F-doped $\mathrm{PbO}_{2}$ anodes in electrochemical filter-press cells. Journal of Hazardous Materials, 153(1-2): 252-260.

Augugliaro V, Litter M, Palmisano L, Soria J, 2006. The combination of heterogeneous photocatalysis with chemical and physical operations: A tool for improving the photoprocess performance. Journal of Photochemistry and Photobiology C: Photochemistry Reviews, 7: 127-144.

Balasubramanian G, Dionysiou D D, Suidan M T, Baudin I, Laìné J M, 2004. Evaluating the activities of immobilized $\mathrm{TiO}_{2}$ powder films for the photocatalytic degradation of organic contaminants in water. Applied Catalysis B: Environmental, 47: 73-84.

Boscoletto A B, Gottardi F, Milan L, Pannocchia P, Tartari V, Tavan M, 1994. Electrochemical treatment of bisphenol A containing wastewater. Journal of Applied Electrochemistry, 24: 1052-1058.

Boye B, Dieng M M, Brillas E, 2003. Anodic oxidation, electro-Fenton and photoelectro-Fenton treatments of 2,4,5trichlorophenoxyacetic acid. Journal of Electroanalytical Chemistry, 557: 135-146.
Brillas E, Baños M A, Garrido J A, 2003. Mineralization of herbicide 3,6-dichloro-2-methoxybenzoic acid in aqueous medium by anodic oxidation, electro-Fenton and photoelectro-Fenton. Electrochim Acta, 48: 1697-1705.

Brillas E, Mur E, Sauleda R, Sanchez L, Peral J, Domenech X, Casado J, 1998. Aniline mineralization by AOP's: anodic oxidation, photocatalysis, electro-Fenton and photoelectron- Fenton processes. Applied Catalysis B: Environmental, 16: 31-42.

Chen X, Chen G, Gao F, Yue P L, 2003. High-performance $\mathrm{Ti} / \mathrm{BDD}$ electrodes for pollutant oxidation. Environmental Science and Technology, 37(21): 5021-5026.

Drogui P, Elmaleh S, Rumeau M, Rambaud A, 2001. Hydrogen peroxide production by water electrolysis: application to disinfection. Journal of Applied Electrochemistry, 31: 877882.

Flox C, Ammar S, Arias C, Brillas E, Vargas-Zavala A V, Abdelhedi R, 2006. Electro-Fenton and photoelectro-Fenton degradation of indigo carmine in acidic aqueous medium. Applied Catalysis B: Environmental, 67: 93-104.

Gruttadauria M, Liotta L F, Carlo G Di, Pantaleo G, Deganello G, Meo P L et al., 2007. Oxidative degradation properties of Co-based catalysts in the presence of ozone. Applied Catalysis B: Environmental, 75: 281-289.

Hoffmann M R, Martin S T, Choi W, Bahnemann D W, 1995. Environmental application of semiconductor photocatalysis. Chemical Reviews, 95: 69-96.

$\mathrm{Hu}$ C, Xing S, Qu J H, He H, 2008. Catalytic ozonation of herbicide 2,4-D over cobalt oxide supported on mesoporous zirconia. Journal of Physical Chemistry C, 112: 5978-5983.

Irmak S, Yavuz H I, Erbatur O, 2006. Degradation of 4-chloro2-methylphenol in aqueous solution by electro-Fenton and photoelectro-Fenton processes. Applied Catalysis B: Environmental, 63: 243-248.

Jia J P, Yang J, Liao J, Wang W H, Wang Z J, 1999. Treatment of dyeing wastewater with ACF electrodes. Water Researchearch, 33: 881-884.

Konova P, Stoyanova M, Naydenov A, Christoskova St, Mehandjiev D, 2006. Catalytic oxidation of VOCs and CO by ozone over alumina supported cobalt oxide. Applied Catalysis A: General, 298: 109-114.

Kuramitz H, Matsushita M, Tanaka S, 2004. Electrochemical removal of bisphenol A based on the anodic polymerization using a column type carbon fiber electrode. Water Research, 38: 2331-2338.

Lapkin A, Bozkaya, B, Mays T, Borello L, Edler K, Crittenden B, 2003. Preparation and characterisation of chemisorbents based on heteropolyacids supported on synthetic mesoporous carbons and silica. Catalysis Today, 81(4): 611-621.

Li X Z, Liu H L, Yue P T, Sun Y P, 2000. Photoelectrocatalytic oxidation of Rose Bengal in aqueous solution using a $\mathrm{Ti} / \mathrm{TiO}_{2}$ mesh electrode. Environmental Science and Technology, 34(20): 4401-4406.

Li G T, Qu J H, Wu R C, 2005. Photoelectrochemical synergetic degradation of Acid Orange II with $\mathrm{TiO}_{2}$ modified $\beta-\mathrm{PbO}_{2}$ electrode. Chinese Science Bulletin, 50(12): 1185-1190.

Li G T, Qu J H, Zhang X W, Ge J T, 2006a. Electrochemically assisted photocatalytic degradation of Acid Orange 7 with $\beta-\mathrm{PbO}_{2}$ electrodes modified by $\mathrm{TiO}_{2}$. Water Research, 40: 213-220.

Li G T, Qu J H, Zhang X W, Liu H J, Liu H N, 2006b. Electrochemically assisted photocatalytic degradation of Orange II Influence of initial $\mathrm{pH}$ values. Journal of Molecular Catalysis A: Chemical, 259: 238-244. 
Liotta L F, Carlo G D, Pantaleo G, Venezia A M, Deganello $\mathrm{G}, 2006 . \mathrm{CO}_{3} \mathrm{O}_{4} / \mathrm{CeO}_{2}$ composite oxides for methane emissions abatement: relationship between $\mathrm{CO}_{3} \mathrm{O}_{4}-\mathrm{CeO}_{2}$ interaction and catalytic activity. Applied Catalysis B: Environmental, 66: 217-227.

Mills A, Hunte S L, 1997. An overview of semiconductor photocatalysis. Journal of Photochemistry and Photobiology A: Chemistry, 108: 1-35.

Murugananthan M, Yoshihara S, Rakuma T, Shirakashi T, 2008. Mineralization of bisphenol A (BPA) by anodic oxidation with boron-doped diamond (BDD) electrode. Journal of Hazardous Materials, 154(1-3): 213-220.

Oturan M A, 2000. An ecologically effective water treatment technique using electrochemically generated hydroxyl radicals for in situ destruction of organic pollutants: Application to herbicide 2,4-D. Journal of Applied Electrochemistry, 30(4): 475-482.

Panizza M, Cerisola G, 2001. Removal of organic pollutants from industrial wastewater by electrogenerated Fenton's reagent. Water Research, 35: 3987-3992.

Qu J H, Zhao X, 2008. Design of $\mathrm{BDD}^{-\mathrm{TiO}_{2}}$ hybrid electrode with P-N function for photoelectroatalytic degradation of organic contaminants. Environmental Science and Technology, 42: 4934-4939.

Qu J H, Li H Y, Liu H J, He H, 2004. Ozonation of alachlor catalyzed by $\mathrm{Cu} / \mathrm{Al}_{2} \mathrm{O}_{3}$ in water. Catal Today, 90: 291-296.

Rajeshwar K, Ibanez J G, Swain G M, 1994. Electrochemistry and the environment. Journal of Applied Electrochemistry, 24: 1077-1091.

Rakitskaya T L, Ennan A A, Granatyuk I V, Bandurko A Yu, Balavoine G G A, Geletii Yu V, Paina V Ya, 1999. Kinetics and mechanism of low-temperature ozone decomposition by Co-ions adsorbed on silica. Catalysis Today, 53: 715723.

Rodger J D, Bunce N J, 2001. Electrochemical treatment of 2,4,6 -trinitrotoluene and related compounds. Environmental Science and Technology, 35: 406-410.

Sadakane M, Steckhan E, 1998. Electrochemical properties of polyoxometalates as electrocatalysts. Chemical Reviews, 98(1): 219-237.

Schwegler M A, Vinke P, van der Eijk M, van Bekkum H, 1992. Activated carbon as a support for heteropolyanion Catalysts. Applied Catalysis A: General, 80(1): 41-57.

Simonsson D, 1997. Electrochemistry for a cleaner environment. Chemical Society Reviews, 26: 181-189.

Sirés I, Arias C, Cabot P L, Centellas F, Garrido J A, Rodrłguez R M, Brillas E, 2007. Degradation of clofibric acid in acidic aqueous medium by electro-Fenton and photoelectroFenton. Chemosphere, 66: 1660-1669.

Sirés I, Garrido J A, Rodriguez R M, Cabot P L, Centellas F, Arias C, Brillas E, 2006. Electrochemical degradation of Paracetamol from water by catalytic action of $\mathrm{Fe}^{2+}, \mathrm{Cu}^{2+}$, and UVA light on electrogenerated hydrogen peroxide. Journal of the Electrochemical Society, 153(1): D1D9.
Skoumal M, Rodríguez R M, Cabot P L, Centellas F, Garrido J A, Arias C, Brillas E, 2008. Electro-Fenton, UVA photoelectro-Fenton and solar photoelectro-Fenton degradation of the drug ibuprofen in acid aqueous medium using platinum and boron-doped diamond anodes. Electrochim Acta, doi: 10.1016/j.electacta. 2008.07.014

Tanaka S, Nakata Y, Kuramitz H, Kawasaki M, 1999. Electrochemical decomposition of bisphenol A and nonylphenol using a Pt/Ti electrode. Chemistry Letters, 943-944.

Tanaka S, Nakata Y, Kimura T, Yustiawati, Kawasaki M, Kuramits H, 2002. Electrochemical decomposition of bisphenol A using $\mathrm{Pt} / \mathrm{Ti}$ and $\mathrm{SnO}_{2} / \mathrm{Ti}$ anodes. Journal of Applied Electrochemistry, 32: 197-201.

Vinodgopal K, Hotchandani S, Kamat P V, 1993. Electrochemically assisted photocatalysis: $\mathrm{TiO}_{2}$ particulate film electrodes for photocatalytic degradation of 4-chlorophenol. Journal of Physical Chemistry, 97: 9040-9044.

Wang J, Farrell J, 2004. Electrochemical inactivation of triclosan with boron doped diamond film electrodes. Environmental Science and Technology, 38(19): 5232-5237.

Wang A M, Qu J H, Ru J, Liu H J, Ge J T, 2005a. Mineralization of an azo dye Acid Red 14 by electro-Fenton's reagent using an activated carbon fiber cathode. Dye and Pigments, 65: 227-233.

Wang A M, Qu J H, Shi H X, Ru J, Liu H J, Lei P J, 2005 b. Degradation of microcystins by electron-Fenton reaction using an activated carbon fiber cathode. Chemical Journal of Chinese Universities, 26(9): 1669-1672.

Wang A M, Qu J H, Song L L, Ru J, 2006a. Electrochemical generation of hydroxyl radicals for Acid Red B degradation by activated carbon fiber electrodes. Acta Chimica Sinica, 64(8): 767-771.

Wang A M, Qu J H, Liu H J, Lei P J, 2006b. Dyes wastewater treatment by reduction-oxidation process in an electrochemical reactor packed with natural manganese mineral. Journal of Environmental Sciences, 18(1): 17-22.

Wang A M, Qu J H, Liu H J, Ru J, 2008. Mineralization of an azo dye Acid Red 14 by photoelectro-Fenton process using an activated carbon fiber cathode. Applied Catalysis B: Environmental, doi: 10.1016/j.apcatb.2008.04.016

Ward M D, Bard A J, 1982. Photocurrent enhancement via trapping of photogenerated electrons of titanium dioxide particles. Journal of Physical Chemistry, 86(18): 35993605.

Xie Y B, Li X Z, 2006. Fenton for azo dye degradation using $\mathrm{TiO}_{2}$-Ti mesh and reticulated vitreous carbon electrodes. Materials Chemistry and Physics, 95: 39-50.

Xing S T, Hu C, Qu J H, He H, Yang M, 2008. Characterization and reactivity of $\mathrm{MnO} x$ supported on mesoporous zirconia for herbicide 2,4-D mineralization with ozone. Environmental Science and Technology, 42(9): 3363-3368.

Zlamal M, Macak J M, Schmuki P, Krýsa J, 2007. Electrochemically assisted photocatalysis on self-organized $\mathrm{TiO}_{2}$ nanotubes. Electrochemistry Communications, 9(12): 2822-2826. 